\title{
Malignant fibrous histiocytoma originating from the mesorectum: a case report
}

\author{
Yoshifumi Nakayama*, Noritaka Minagawa, Takayuki Torigoe, Koji Yamaguchi
}

\begin{abstract}
Background: Malignant fibrous histiocytoma (MFH) is a common sarcoma affecting soft tissues of the body, especially of the extremities or trunk. Prognosis of the abdominal MFH is usually poor.

Case presentation: A 52-year-old female presented to our surgical outpatient clinic with a lower abdominal tumor that had been gradually increasing in size. Clinical examination revealed a firm, irregularly surfaced, fixed, painless, child-head-sized tumor located in her lower abdomen. Computed tomography (CT) and magnetic resonance imaging (MRI) of the abdomen revealed a polycystic tumor at the lower abdomen which was $15 \times 13 \times 11 \mathrm{~cm}$ in diameter and encased the colorectum to the left back side. A barium enema and a colonoscopy showed direct invasion to the rectum. In 2001, the tumor had been excised along with a low anterior resection of the rectum because of direct invasion. The origin of this tumor was the mesorectum. The weight of the excised tumor was $1,500 \mathrm{~g}$, including $800 \mathrm{ml}$ of a brown fluid. A histopathological diagnosis revealed a common type of MFH, in which mitotic figures are frequently seen.

Conclusion: This patient has survived without recurrence, for approximately 8 years since the completed tumor resection. It is important to obtain a complete resection during the MFH treatment.
\end{abstract}

\section{Background}

Malignant fibrous histiocytoma (MFH) is a common sarcoma affecting soft tissues of the body, especially of the extremities or trunk [1-3]. The tumor cells are derived from histiocytes capable of fibroblastic transformation [4]. MFH is an aggressive tumor with a high potential of demonstrating metastasis to other parts of the body. The prognosis of patients with abdominal MFH is usually poor [5].

Primary mesenteric MFH is a rare disease and few cases have been reported in the English literature [6-10]. We herein report a surgical case of MFH that originated from the mesorectum and affected the rectum.

\section{Case Report}

A 52-year-old female presented to our surgical outpatient clinic with a lower abdominal tumor that had been gradually increasing in size. She first noticed a fist sized, painless tumor about four months ago. Clinical examination revealed a firm, irregularly surfaced, fixed,

\footnotetext{
* Correspondence: nakayama@med.uoeh-u.ac.jp

* Correspondence: nakayama@med.uoeh-u.ac.jp
Department of Surgery 1, School of Medicine, University of Occupational and Environmental Health, Japan
}

painless, child-head-sized tumor in her lower abdomen. Laboratory data showed that she had a white blood cell count of $5500 / \mathrm{mm}^{3}$, hemoglobin of $8.3 \mathrm{~g} / \mathrm{dl}$, hematocrit of $25.4 \%$, platelets count of $429,000 / \mathrm{mm}^{3}$, normal electrolytes, as well as normal blood urea nitrogen levels and the liver function.

Computed tomography (CT) of the abdomen demonstrated a large tumor in the lower abdomen which was $15 \times 13 \times 11 \mathrm{~cm}$ in diameter and encased the colorectum to the left back side (Figure 1A). Magnetic resonance imaging (MRI) of the lower abdomen indicated a polycystic tumor (Figure 1B). A barium enema revealed that the tumor had encased the rectum toward left posterior, and some parts of the upper rectum had irregular mucosa (Figure 2A). A colonoscopy revealed an encasement of the upper rectum and also round ulcers with a white coating, whose histological examination determined granulation tissue (Figure 2B).

In 2001, this tumor was excised along with a low anterior resection of the rectum for the complete resection (Figure 3A, B). The mesorectum including the tumor was well circumscribed from surrounding organs, with the exception of the rectum. Therefore, the origin of 

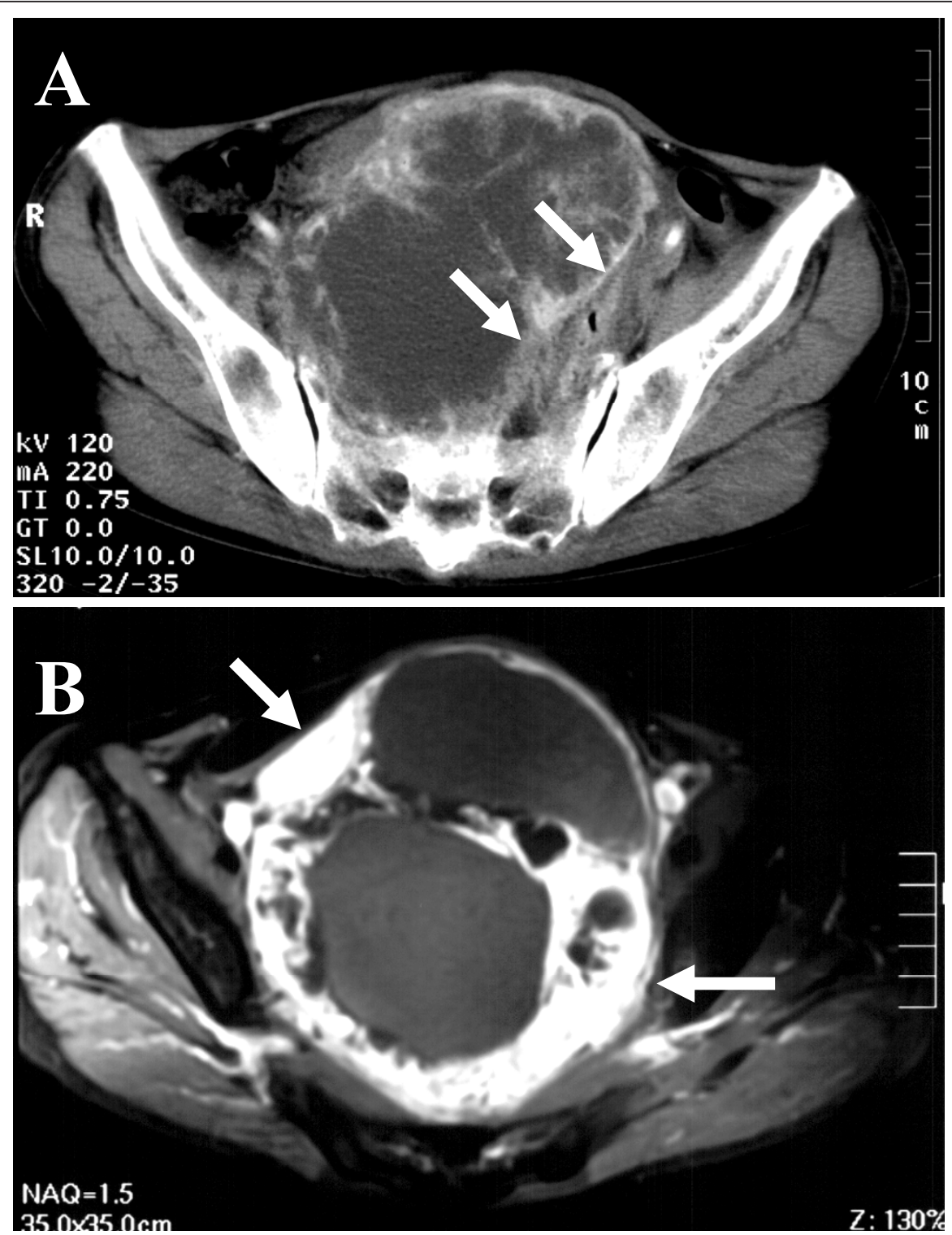

Figure 1 A) An abdominal CT revealed a large uneven tumor in the lower abdomen and encased the colorectum to the left back side (arrows). B) An MRI of the lower abdomen revealed a polycystic tumor with a part of the thickened wall (arrows).

this tumor was thought to be the mesorectum. The uterus and the ovaries had no local lesions. The weight of the excised tumor was $1,500 \mathrm{~g}$. This tumor included $800 \mathrm{ml}$ of a brown fluid, whose cytological examination determined class I. A histopathological examination revealed proliferation of pleomorphic cells in a storiform pattern (Figure 4A). Mitotic figures were also frequently observed. Immunohistochemical analyses indicated that many of the tumor cells were positive for vimentin (Figure 4B), while tumor cells were negative for cytokeratins, desmin, S-100 protein, actins, c-kit, and CD34. These features are compatible with MFH of a common type.
The postoperative course was uneventful, and she left the hospital on the 15th postoperative day. A postoperative follow-up CT revealed no recurrence of the MFH in any organs since the resection was completed.

\section{Discussion}

Retroperioneal and mesenteric MFH have been reported to occur in the rate from $5.7 \%$ to $16 \%$ of the total MFHs cases $[1,2,5,11]$. Several reports have so far indicated that MFH derived from the retroperitoneum includes mesenteric MFH because it is difficult to determine the true origin of the huge tumor. Due to this condition, mesenteric MFH is very rarely observed 


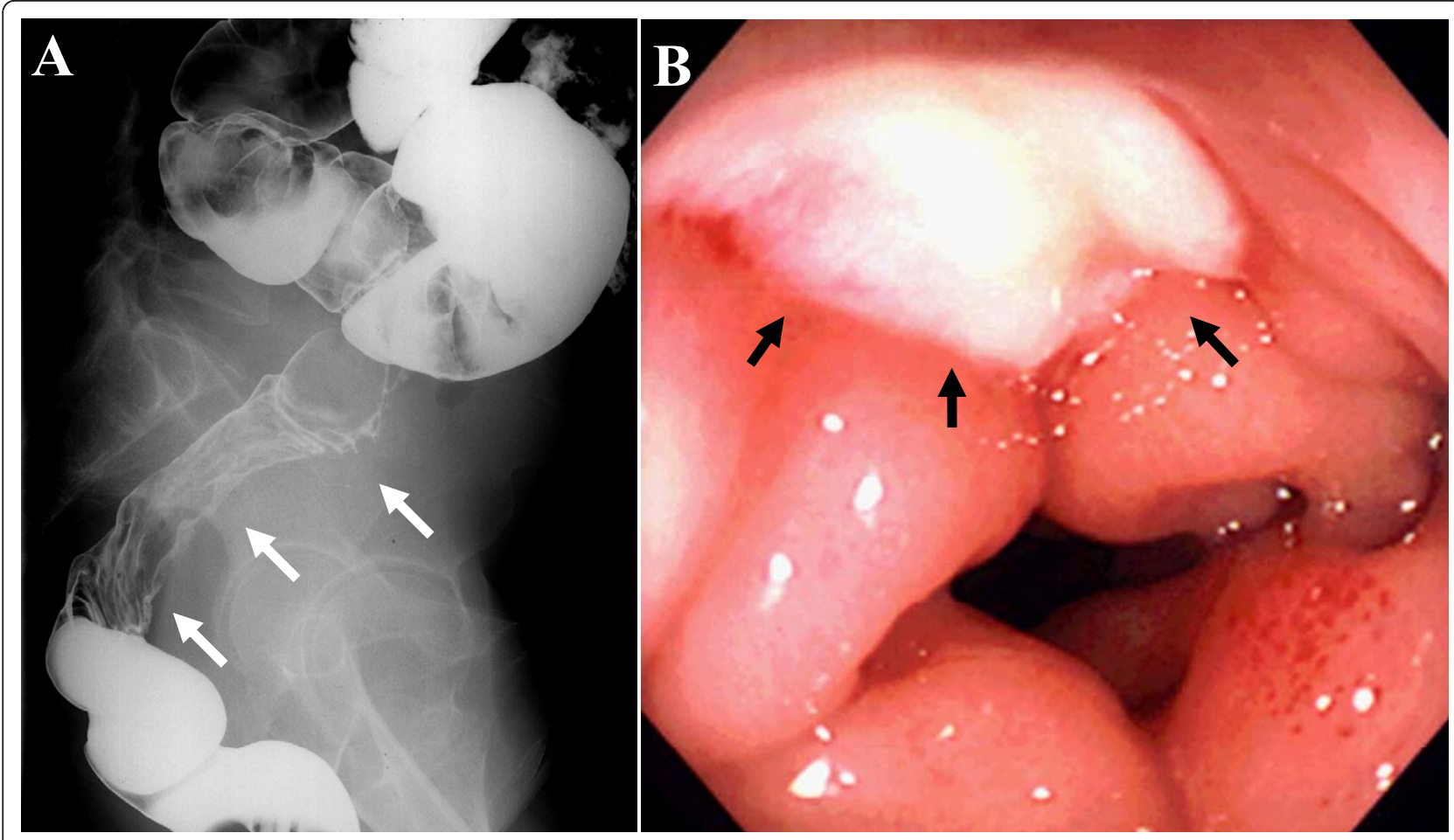

Figure 2 A) A barium enema revealed an encasement of the sigmoid colon and rectum toward the left back side. Some parts of the upper rectum had irregular mucosa (arrows). B) A colonoscopy revealed a round ulcer with a white coating (arrows).

[6-10]. In our case, the tumor originated from the mesorectum because the huge tumor was limited to within the capsule of the mesorectum.

MFH is an aggressive tumor with a high potential of metastasis to other parts of the body. The rates of local recurrence and distant metastasis are $44 \%$ and $42 \%$, respectively [1]. The most frequent metastatic site is the lung (82\%), followed by the lymph nodes (32\%) [1]. Although the 5-year survival rate of all MFH patients that underwent surgery is $67.2 \%$ [11], the 5-year survival rate of patients with abdominal MFH is reportedly $14 \%$ [5]. On the other hand, the 5-year survival rate of patients with mesenteric MFH has not been reported because the disease is extremely rare. The current treatment of choice for

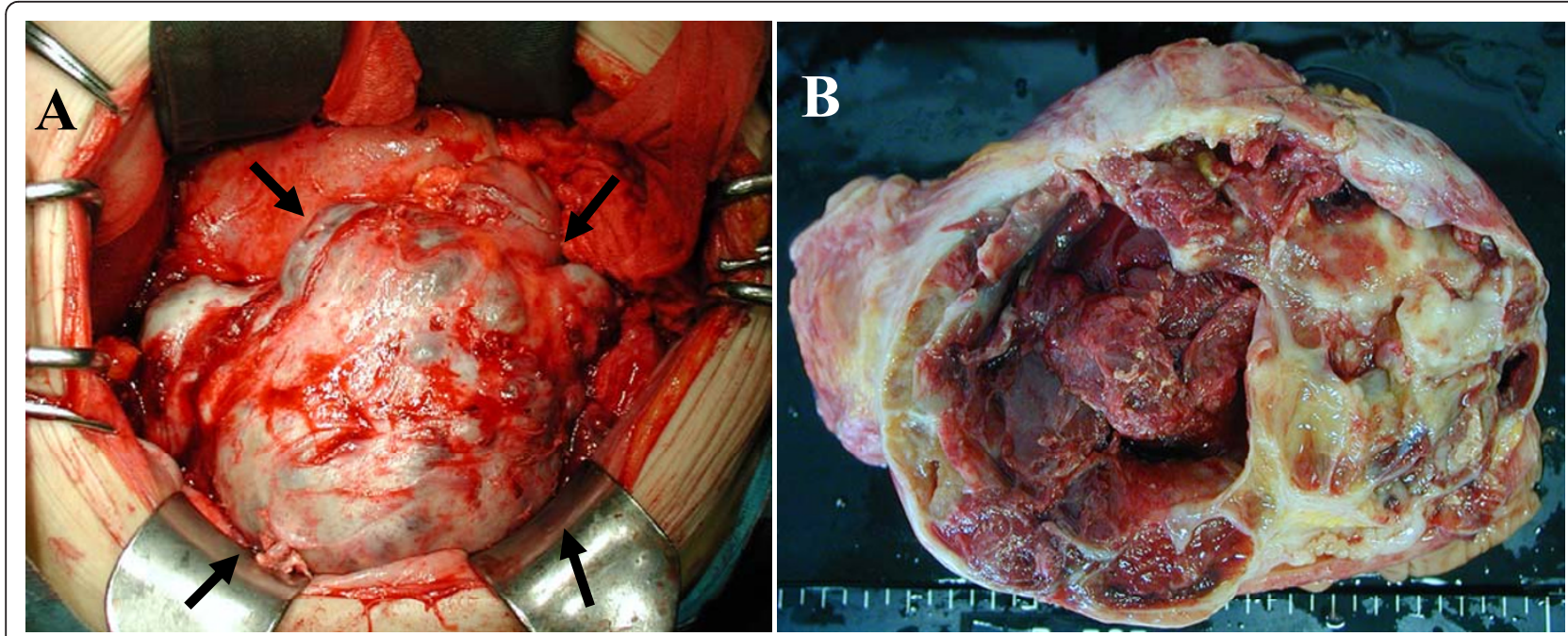

Figure 3 A) A laparotomy revealed a child-head-sized tumor that encased the other organs (arrows). B) An operative specimen revealed a polycystic tumor with a part of the thickened wall. 


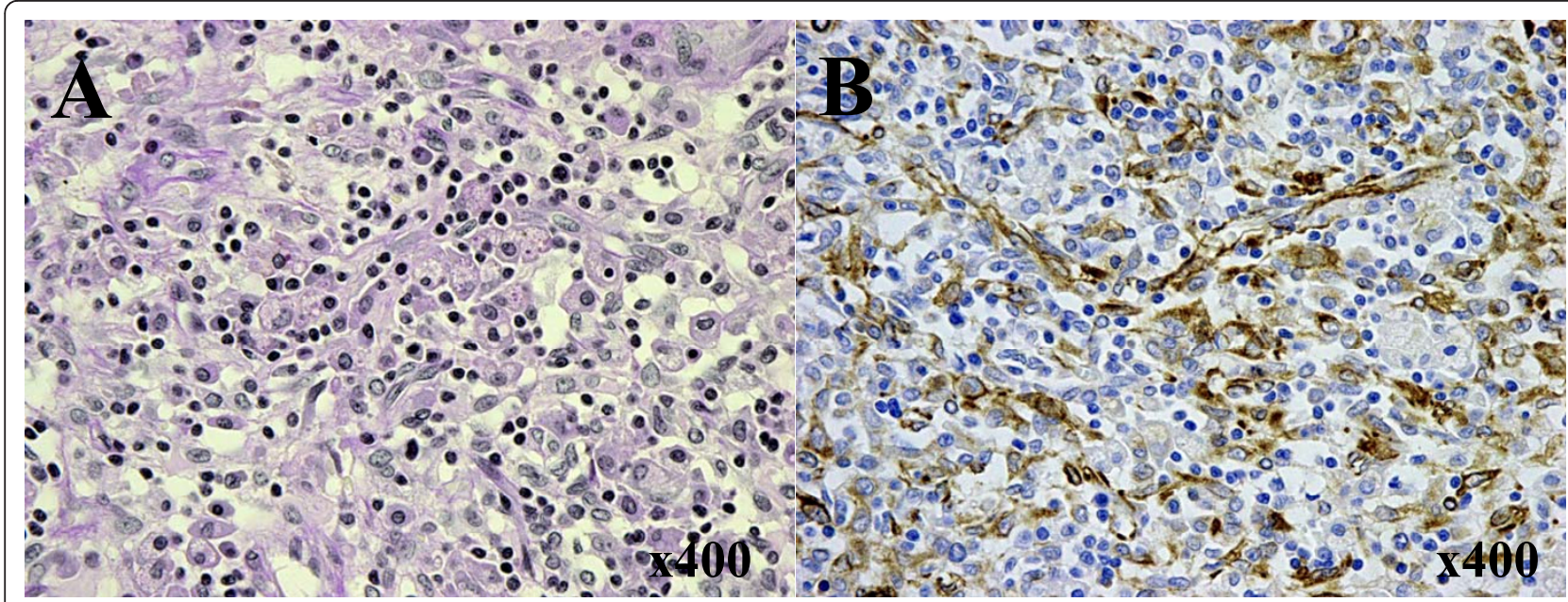

Figure 4 A) A histopathological examination revealed pleomorphic cells proliferating in a storiform pattern (H \& E, $\times 400)$. B) Tumor cells showing positive staining for vimentin $(\times 400)$.

primary MFH is surgical resection which means wide excision of the tumor with an aim for a tumor-free margin. Presently, the efficacy of adjuvant chemotherapy or radiation has not been clear in the case of retroperitoneal and visceral MFH. Therefore, this patient received neither adjuvant chemotherapy nor radiation.

Mesenteric MFH initially grows without any significant clinical symptoms, and finally produces clinical symptoms and signs later when it compresses or invades the adjacent organs [9]. In this case, she noticed the lower abdominal tumor without any symptoms: nevertheless, the tumor size was $15 \times 13 \times 11 \mathrm{~cm}$ and the tumor had directly invaded to the rectum. Therefore, a complete tumor resection combined with a low anterior resection of the rectum was needed. A previous report indicated that colonic lesions of retroperitoneal MFH were detected by a barium enema and colonoscopic examination before the laparotomy [12]. In the present case, rectal ulcers were also identified by a barium enema and colonoscopic examination before the laparotomy. Moreover, a histologic examination of the resected specimen clearly demonstrated a submucosal invasion by the MFH. It is very important that the requirement of the combined resection with other organs is decided before the operation begins.

The efficacy of chemotherapy against advanced or metastatic MFH is still unclear. On the other hand, several phase studies which investigate the efficacy of chemotherapy against advanced or metastatic soft tissue sarcoma including MFH, have been reported [13-16]. These studies indicated that doxorubicin and ifosfamide are the most active agents for the treatment of this clinical condition [13-16]. However, the response rate of these agents has been reported to range between 10\% and $36 \%$, and the median overall survival of these agents has been described to be between 10 and 12 months [13-16]. Therefore, in order to obtain an improvement in the survival in the patients with soft tissue sarcoma including MFH, further investigation of the new available agents is thus called for.

\section{Conclusion}

This patient has survived without recurrence for approximately 8 years after the completed tumor resection. A complete resection is important to obtain a favorable prognosis for $\mathrm{MFH}$.

\section{Consent}

Written informed consent was obtained from the patient for publication of this case report and accompanying images. A copy of the written consent is available for review by the Editor-in-Chief of this journal.

\section{Authors' contributions}

$N Y, M N, T$ and YK contributed equally to this work; NY designed the research; NY, MN and TT performed and analyzed the data; NY and YK wrote the paper.

\section{Competing interests}

The authors declare that they have no competing interests.

Received: 29 July 2010 Accepted: 2 February 2011

Published: 2 February 2011

\section{References}

1. Weiss SW, Enzinger FM, Malignant fibrous histiocytoma: An analysis of 200 cases. Cancer 1978, 41:2250-2266

2. Enjoji M, Hashimoto H, Tsuneyoshi M, Iwasaki H: Malignant fibrous histiocytoma. A clinicopathological study of 130 cases. Acta Pathol Jpn 1980, 30:727-741

3. Ros PR, Viamonte M Jr, Rywlin AM: Malignant fibrous histiocytoma: Mesenchymal tumor of ubiquitous origin. Am J Roentgenol 1984, 142:753-759.

4. O'Brien JE, Stout AP: Malignant fibrous xanthoma. Cancer 1964, 17:1445-1455. 
5. Kearney MM, Soule EH, Ivins JC: Malignant fibrous histiocytoma: A retrospective study of 167 cases. Cancer 1980, 45:167-178.

6. Bodner K, Bodner-Adler B, Mayerhofer S, Gruünberger W, Wierrani F, Czerwenka K, Leodolter S, Mayerhofer K: Malignat fibrous histiocytoma (MFH) of mesentery: A case report. Anticancer Res 2002, 22:169-170.

7. Hauser $H$, Beham A, Uranüs S, Frühwieth $H$, Lederer A, Klimpfinger M: Malignat fibrous histiocytoma of the mesentery-a rare cause of abdominal pain, Case report with a review of literature. Z Gastroenterol 1993, 31:735-738.

8. Basso M, Codaccipisanelli M, Bovino A, Vietri F, D'Ermo G, De Toma G: Malignant fibrous histiocytoma of the mesentery: Report of two cases and review of the literature. $G$ Chir 2005, 26:43-46.

9. Shibuya T, Ishida H, Konno K, Komatsuda T, Hamashima Y, Sato M, Masamune O: Sonographic findings of malignant fibrous histiocytoma of mesentery-report of two cases. Eur J Ultrasound 1998, 8:207-212.

10. Higa T, Yamada M, Deguchi S, Tamaki S, Muto Y, Nakasone K, Kiyuna M, Toda T: Malignant fibrous histiocytoma of the mesentery: A case report. Ryukyu Med J 1996, 16:75-78

11. Pezzi CM, Rawlings MS Jr, Esgro JJ, Pollock RE, Romsdahl MM: Prognostic factors in 277 patients with malignant fibrous histiocytoma. Cancer 1992, 69:2098-2103

12. Kobayashi S, Goto K, Shiraki S, Okayama Y, Ando H, Okumura F, Nakamura S, Hattstori T, Joh T, Itoh M: Retroperitoneal malignant fibrous histiocytoma causing variegated colonic lesion. Internal Medicine 1998, 37:376-380.

13. Lorigan P, Verweiji J, Papao Z, Rodenhuis S, Le Cesne A, Leahy MG, Radford JA, Van Glabbeke MM, Kirkpatrick A, Hogendoorn PCW, Blay JY: Phase III trial of two investigational schedules of ifosfamide compared with standard-dose doxorubicin in advanced or metasttic soft tissue sarcoma: A European organization for research and treatment of cancer soft tissue and bone sarcoma group study. J Clin Oncol 2007, 25:3144-3150

14. Maurel J, López-Pousa A, de Las Peñas R, Fra J, Martín J, Cruz J, Casado A, Poveda A, Martínez-Trufero J, Balañá C, Gómez MA, Cubedo R, Gallego O, Rubio-Viqueira B, Rubió J, Andrés R, Sevilla I, de la Cruz JJ, Del Muro XG, Buesa JM: Efficacy of sequential high-dose doxorubicin and ifosfamide compared with standard-dose doxorubicin in patients with advanced soft tissue sarcoma: An open-label randomized phase II study of the Spanish group for research on sarcoma. J Clin Oncol 2009, 27:1893-1898.

15. Karavasilis V, Seddon BM, Ashley S, Al-Muderis O, Fisher C, Judson I: Significant clinical benefit of fierst-line palliative chemotherapy in advanced soft-tissue sarcoma. Cancer 2008, 112:1585-1591.

16. Sleijfer S, Ouali M, Van Glabbeke M, Krarup-Hansen A, Rodenhuis S, Le Cesne A, Hogendoorn PCW, Verweiji J, Blay JY: Prognostic and predictive factors for outcome to first-line ifosfamide-containing chemotherapy for adult patients with advanced soft tissue sarcomas. An exploratory, retrospective analysis on large series from the european organization for research and treatment of cancer-soft tissue and bone sarcoma group (EORTG-STBSG). Eur J Cancer 2010, 46:72-83.

doi:10.1186/1477-7819-9-15

Cite this article as: Nakayama et al: Malignant fibrous histiocytoma

originating from the mesorectum: a case report. World Journal of Surgical Oncology 2011 9:15.

\section{Submit your next manuscript to BioMed Central and take full advantage of:}

- Convenient online submission

- Thorough peer review

- No space constraints or color figure charges

- Immediate publication on acceptance

- Inclusion in PubMed, CAS, Scopus and Google Scholar

- Research which is freely available for redistribution

Submit your manuscript at www.biomedcentral.com/submit
Biomed Central 